\title{
Assessing COVID-19-related anxiety and functional impairment amongst nurses in Malawi
}

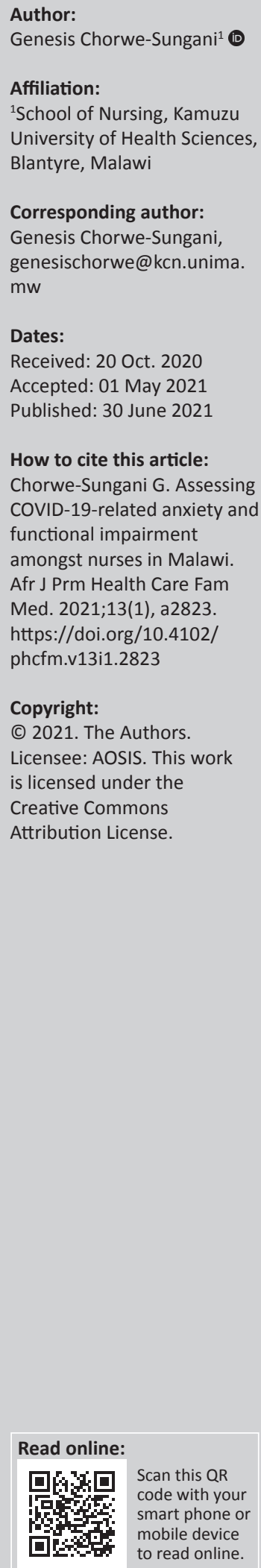

\begin{abstract}
Background: Psychological well-being of nurses is crucial for them to effectively discharge their duties. However, coronavirus disease 2019 (COVID-19)-related anxiety can interfere with nurses' performance and reduce their self-efficacy.
\end{abstract}

Aim: The primary aim of this study was to assess COVID-19-related anxiety and functional impairment amongst nurses in Malawi. The secondary aim of the study was to determine reliability and validity of the Coronavirus Anxiety Scale.

Setting: The study was conducted in Malawi.

Methods: This was a cross-sectional study that collected quantitative data from 102 nurses in Malawi online. Data were analysed using descriptive statistics and receiver operating curve analysis.

Results: This study found that $25.5 \%$ (26) of respondents had COVID-19-related anxiety and $48 \%$ (49) functional impairment. There were significant differences in the numbers of respondents who had functional impairment in relation to workplace $\left(X^{2}=8.7, p=0.03\right)$, with many of those working in hospitals $(58.6 \%, n=34$ ) having highest levels (mean $=20.6 \pm 10.4$ ). The Coronavirus Anxiety Scale proved to be an effective instrument (Sensitivity = 73.1\%; Specificity $=60.5 \%$; area under the curve $=0.73$ ) for assessing COVID-19-related anxiety amongst nurses.

Conclusion: It is necessary to screen nurses for COVID-19-related anxiety and functional impairment and provide them effective psychosocial interventions. Policymakers should place more emphasis on allocation of financial resources to mental health services and staff support programmes targeting nurses during pandemics. There is a need to conduct future research on mental health interventions that might be used to assist nurses with COVID-19related anxiety and functional impairment.

Keywords: anxiety; COVID-19; nurse; prevalence; functional impairment.

\section{Introduction}

The coronavirus disease 2019 (COVID-19) is fast spreading across the globe, causing an outbreak. Healthcare professionals from various disciplines and cadres are involved in the care of patients with COVID-19. ${ }^{1}$ The high prevalence of COVID-19, its novelty and rapid spread, and the associated morbidity and mortality rates have acutely overstretched the limits of healthcare systems worldwide. ${ }^{2}$ This is a situation in Malawi where healthcare services have been overwhelmed from the first time a case of COVID-19 was detected on 02 April 2020. Data from Public Health Institute of Malawi reported by media indicate that as of September 2020, more than 5500 people have tested positive for COVID-19 and the numbers keep on rising. In addition, more than 150 people including one health worker have died of the disease in Malawi. In 2020, a media report from the Ministry of Health indicated that there are 67 nurses who have tested positive for COVID-19 in Malawi. The upsurge of COVID-19 patients has caused an increase in care demands on nurses both in hospitals and community. ${ }^{2}$ Consequently, it has negatively affected some nurses psychologically.

It is documented that nurses are now afraid of going to work because they fear for their lives and family. ${ }^{3}$ They suffer from great amount of anxiety every time they go for work because they fear that they will get sick of COVID-19 and end up dying like their patients. ${ }^{3}$ The high infection and mortality rates related to COVID-19 cause extensive fear and anxiety. ${ }^{4}$ As such, identifying 
high-risk groups for psychological symptoms is as important as recognising the presence of these symptoms, as they will be the target populations for evaluation and perhaps treatment. ${ }^{5}$ Frontline healthcare workers are particularly vulnerable to mental health problems associated with COVID-19. ${ }^{6}$ A systematic review reported a pooled prevalence of COVID-19-related anxiety amongst health workers as $23.2 \% .^{7}$ In Nepal, nurses were found to be significantly more likely to experience anxiety symptoms related to COVID-19 than other health workers (adjusted odds ratio [AOR]: 2.33 ; 95\% confidence interval [CI]: 1.214.47). ${ }^{8}$ Coronavirus disease 2019-related anxiety can interfere with performance of nurses in their duties and reduce their self-efficacy levels. ${ }^{9}$ Psychological well-being of nurses is crucial to effectively discharge their duties. Healthcare workers including nurses should be afforded opportunities for validating their legitimate anxiety and fears related to COVID-19 through periodic screening ${ }^{6}$ of COVID-19-related anxiety ${ }^{8}$ to promote early intervention. However, in Malawi, nurses are not periodically screened for COVID-19-related anxiety.

In Malawi, nurses constitute the bulk of frontline healthcare workers who are fighting the COVID-19 outbreak. However, these nurses amongst other challenges are faced with increased workload and threat of COVID-19, which may aggravate psychological pressure they experience. Some nurses have lamented that one of the hardest things to cope with during the COVID-19 pandemic has been the inconsistencies and constant changes ${ }^{3}$ they experience in their work places. For instance, conflicting and rapidly changing information about personal protective equipment exacerbates healthcare workers' ongoing fears of exposure and uncertainty about their own safety in the workplace. ${ }^{6}$ Furthermore, protocols for procedures keep on changing rapidly, causing anxiety about whether what they used to do prior to such changes was adequate for themselves and patients. ${ }^{3}$ This shows that nurses and other people who spend much time in thinking about pandemics are at the highest risk of mental illness ${ }^{5}$ including anxiety. Therefore, this study aimed at assessing COVID-19-related anxiety amongst nurses in Malawi. The secondary aim of the study was to determine the reliability and validity of the Coronavirus Anxiety Scale (CAS).

\section{Methods}

\section{Design}

This was a cross-sectional study that collected data from respondents at one point in time to assess COVID-19-related anxiety and functional impairment amongst nurses in Malawi.

\section{Setting}

The study setting was Malawi as a country including all members of the National Organisation of Nurses in Malawi (NONM) working in Christian Health Association of Malawi (CHAM) and government health facilities.

\section{Study population}

The target population were all enrolled nurses, nurse midwife technicians (NMTs) and registered nurses in Malawi. Enrolled nurse and NMTs are the lowest cadre of nurses with a college certificate or diploma in Nursing and Midwifery, whilst registered nurses either have Bachelor of Science in Nursing and Midwifery or Bachelor of Science in Nursing and a University Certificate in Midwifery or University Diploma in Nursing and Midwifery or University Diploma in Nursing and a University Certificate in Midwifery. ${ }^{10}$

\section{Sample size}

The sample size was calculated using the methodology detailed by Jones et al. ${ }^{11}$ This was used to ensure that there were enough cases and non-cases of anxiety for validating CAS. Using estimated specificity $=0.85,{ }^{12}$ estimated population prevalence of COVID-19-related Anxiety of $0.23^{7}$ and width of $\mathrm{CI}=0.05$, a sample size of 255 was calculated. The researcher was most interested in making sure that the test has a high specificity to rule in COVID-19-related anxiety. ${ }^{11}$ However, 320 individuals viewed the survey questionnaire online and a total of 106 respondents completed the questionnaire of which four respondent who were not residing in Malawi were excluded, thus resulting in 102 respondents who participated in this study. This was a convenient sample. The low response rate in this study may have led to sample bias, low power and inaccurate effect size. ${ }^{13}$

\section{Materials}

The data collection instrument for this study included background information, the CAS and the Work and Social Adjustment Scale (WSAS). The instrument was selfadministered in English because nurses are expected to understand English by virtue of their training.

\section{Background information}

Respondents were asked questions related to the background information including age, gender, level of education, employment status, marital status, coronavirus diagnosis, history of anxiety, if they are working with COVID-19 positive patients, if they have a relative or acquaintance with COVID-19 diagnosis, ${ }^{5}$ nursing cadre and workplace.

\section{Coronavirus Anxiety Scale}

This study used the CAS, which was specifically designed to assess anxiety that is triggered by COVID-19. ${ }^{12}$ The tool is a fiveitem Likert scale, with each item having five possible responses ranging from 0 (not at all) to 4 (nearly every day over the last 2 weeks). The CAS has a maximum score of 20 and a minimum score of 0 , with an optimum cut-off score of $\geq 9 . .^{12,14}$ It is a reliable (Cronbach's alpha $=0.93$ ) and valid tool for measuring COVID19-related anxiety (sensitivity $=90 \%$, specificity $=85 \%$, area under the curve $[\mathrm{AUC}]=0.94, p<0.001) .{ }^{12}$ The instrument was used to distinguish individuals with dysfunctional anxiety and those without anxiety. 


\section{Work and Social Adjustment Scale}

This study also used an adapted WSAS to measure functional impairment experienced by respondents. ${ }^{15}$ The WSAS is a five-item Likert scale, with each item having nine possible responses ranging from 0 (not at all impaired) to 8 (very severely impaired). The tool has a maximum score of 40 and a minimum score of 0 , with an optimum cut-off score of $\geq 21$ for moderately severe or worse psychopathology. ${ }^{14,15}$ Scores of 10-20 suggest significant functional impairment but less severe clinical symptomatology, whilst scores $<10$ are associated with subclinical populations. It is a reliable instrument (Cronbach's alpha $\geq 0.88$ ) ${ }^{14,15}$ The WSAS was used as a gold standard against which the CAS was validated.

\section{Data collection procedure}

Data collection was conducted from August 2020 to September 2020 using a self-administered questionnaire powered by Surveys for Pages and Google Pages. Online links for the study questionnaire were sent to potential respondents through WhatsApp, Facebook, Messenger and email. The questionnaire included information about the study and a question which asked consent from potential respondents before deciding to participate in the study.

\section{Data analysis}

Data were analysed using the Statistical Package for Social Sciences (SPSS) version 25. Descriptive statistics including mean, standard deviation, percentage and frequencies were used to summarise data for background information, the CAS scores and the WSAS scores. Analysis of variance (ANOVA) and independent samples Student's $t$-tests were used to test for mean difference of respondents' scores. A receiver operating characteristic (ROC) analysis was used to generate values for sensitivity, specificity, AUC, positive predictive values (PPV), negative predictive values (NPVs) and Youden's index for the CAS to identify functionally impaired nurses and test whether or not its original cut-off score of $\geq 9$ remained an optimal score ${ }^{12}$ for psychiatric screening in the local setting. Finally, Cronbach's alpha for the CAS and the WSAS were computed to assess their internal consistency locally.

\section{Ethical considerations}

Ethical approval to conduct the study was obtained from the College of Medicine Research and Ethics Committee, University of Malawi(EthicalClearancenumber P.08/20/3096, 24 June 2020).

This study received ethical approval and institutional clearance from relevant authorities. The online questionnaire was preceded by an information sheet that explained the nature and benefits of the study to nurses before they were asked to give consent to participate in the study. Respondents' names did not form part of background information that was collected, thus respecting their privacy and maintaining confidentiality. Respondents were informed that only aggregated data will be analysed and disseminated.
Respondents were also informed that their participation in the study was voluntary and that they were free to withdraw at any time if they felt uncomfortable about any aspect during the course of the study. They were further informed that refusing to join the study would not have any effect on their job.

\section{Results \\ Demographic charateristics of respondents}

The respondents in this study were drawn from hospitals $(56.9 \%, n=58)$, nursing colleges $(24.5 \%, n=25)$, COVID-19 ward $(2 \%, n=2)$ and non-governmental organisations (NGOs) $(16.6 \%, n=17)$. They included $71.62 \%(n=73)$ female and $28.4 \%(n=29)$ male nurses. There were more registered nurses $(91.2 \%, n=93)$ compared with nurse midwive technichians $(8.8 \%, n=9)$. The following were educational qualifications of respondents: Bachelor's degree (52.9\%, $n=54)$, Master's degree $(30.4 \%, n=31)$, Doctor of Philosophy $(5.9 \%, n=6)$, Diploma $(7.8 \%, n=8)$ and Certificate $(2.9 \%$, $n=3)$. The employment status of respondents were as follows: full-time $(88.2 \%, n=90)$, unemployed $(9.8 \%, n=10)$ and part-time $(2 \%, n=2)$. Some respondents were married $(69.6 \%, n=71)$ and others were not $(8.8 \%, n=9)$. Some respondents $(91.2 \%, n=93)$ were never diagnosed with COVID-19 whilst others $(8.8 \%, n=9)$ were diagnosed. More than a quarter of respondents $(25.5 \%, n=26)$ had a history of anxiety, whilst many $(74.5 \%, n=76)$ did not have. There were few respondents $(13.7 \%, n=14)$ who reported that they were working with COVID-19 patients, whilst many $(86.3 \%, n=88)$ were not. More than one-third of respondents $(40.2 \%, n=41)$ had a relative with COVID-19, whilst others $(59.8 \%, n=61)$ did not. The age of respondents ranged from 21 years to 60 years, with a mean age of $36.7 \pm 8.9$ years.

\section{Prevalence of COVID-19-related anxiety amongst respondents}

This study found that COVID-19-related anxiety was high $(25.5 \%, n=26)$ amongst nurses in Malawi. There were significant differences in the number of respondents who had COVID-19-related anxiety in relation to workplace $\left(X^{2}=8.8\right.$, $p=0.03$ ) (Table 1). The prevalence of COVID-19-related anxiety was highest amongst respondents who were working in hospitals $(36.2 \%, n=21)$, with a mean CAS score of $6.7 \pm$ 4.8 (Table 1). The prevalence of COVID-19-related anxiety varied in relation to other demographic characteristics (Table 1). However, this finding was not significant.

\section{Prevalence of functional impairment amongst respondents}

This study found that nearly half of the respondents (48.0\%, $n=49$ ) in this study suffered from functional impairement because of COVID-19. There were variations in number of respondents who suffered functional impairment in relation to demographic characteristics (Table 2). These differences were not significant $(p>0.05)$ except for gender and workplace. The prevalence of functional impairement was significantly higher amongst female respondents $(56.2 \%, n=41)$ compared 
TABLE 1: Demographic characteristics of respondents associated with COVID19-related anxiety.

\begin{tabular}{|c|c|c|c|c|c|c|c|}
\hline \multirow[t]{3}{*}{ Characteristics } & \multicolumn{7}{|c|}{ COVID-19-related anxiety } \\
\hline & \multicolumn{2}{|c|}{ Yes† } & \multicolumn{2}{|c|}{ No: } & \multicolumn{2}{|c|}{ Statistic } & \multirow{2}{*}{$\begin{array}{l}\text { Mean CAS } \\
\text { scores }\end{array}$} \\
\hline & $n$ & $\%$ & $n$ & $\%$ & $\chi^{2}$ & $p$ & \\
\hline Age & & & & & 0.5 & 0.5 & \\
\hline$\leq 35$ years & 15 & 57.7 & 38 & 50.0 & & & $5.5 \pm 4.9$ \\
\hline$\geq 36$ years & 11 & 42.3 & 38 & 50.0 & & & $4.4 \pm 4.7$ \\
\hline Gender & & & & & 0.49 & 0.48 & \\
\hline Female & 20 & 27.4 & 53 & 72.6 & & & $5.3 \pm 5$ \\
\hline Male & 6 & 20.7 & 23 & 79.3 & & & $4.1 \pm 4.1$ \\
\hline Education & & & & & 1.1 & 0.9 & \\
\hline Bachelor's & 14 & 25.9 & 40 & 74.1 & & & $5.4 \pm 4.8$ \\
\hline Certificate & 1 & 33.3 & 2 & 66.7 & & & $8 \pm 6$ \\
\hline Diploma & 3 & 37.5 & 5 & 62.5 & & & $6.9 \pm 4.7$ \\
\hline Master's & 7 & 22.6 & 24 & 77.4 & & & $3.8 \pm 4.4$ \\
\hline Doctorate & 1 & 16.7 & 5 & 83.3 & & & $2.8 \pm 4.6$ \\
\hline Nursing cadre & & & & & 1.9 & 0.17 & \\
\hline NMT & 4 & 44.4 & 5 & 56.6 & & & $8 \pm 4.9$ \\
\hline Registered nurse & 22 & 23.7 & 71 & 76.3 & & & $4.7 \pm 4.7$ \\
\hline Employment status & & & & & 2.3 & 0.52 & \\
\hline Full-time & 25 & 27.8 & 65 & 72.2 & & & $5.1 \pm 4.8$ \\
\hline Part-time & 0 & 0.0 & 2 & 100.0 & & & $3 \pm 4.2$ \\
\hline Unemployed & 1 & 11.1 & 8 & 88.9 & & & $4.1 \pm 4.6$ \\
\hline Workplace & & & & & 8.8 & $0.03 *$ & \\
\hline Hospital & 21 & 36.2 & 37 & 63.8 & & & $6.7 \pm 4.8$ \\
\hline Nursing college & 4 & 16.0 & 21 & 84.0 & & & $2.8 \pm 4.2$ \\
\hline COVID-19 ward & 0 & 0.0 & 2 & 100.0 & & & $1.5 \pm 0.7$ \\
\hline NGOs & 1 & 5.9 & 16 & 94.1 & & & $2.5 \pm 2.7$ \\
\hline Marital status & & & & & 0.3 & 0.59 & \\
\hline Married & 17 & 23.9 & 54 & 76.1 & & & $4.8 \pm 4.9$ \\
\hline Not married & 9 & 29.0 & 22 & 71.0 & & & $5.3 \pm 4.6$ \\
\hline $\begin{array}{l}\text { Ever diagnosed with } \\
\text { COVID-19 }\end{array}$ & & & & & 1.9 & 0.17 & \\
\hline Yes & 4 & 44.4 & 5 & 55.6 & & & $8.1 \pm 5.6$ \\
\hline No & 22 & 23.7 & 71 & 76.3 & & & $4.6 \pm 4.6$ \\
\hline History of anxiety & & & & & 0.1 & 0.7 & \\
\hline Yes & 6 & 23.1 & 20 & 76.9 & & & $5.8 \pm 4.2$ \\
\hline No & 20 & 26.3 & 56 & 73.7 & & & $4.7 \pm 4.9$ \\
\hline $\begin{array}{l}\text { Working with } \\
\text { COVID-19 patients }\end{array}$ & & & & & 0.9 & 0.35 & \\
\hline Yes & 5 & 35.7 & 9 & 64.3 & & & $7.4 \pm 5.1$ \\
\hline No & 21 & 23.9 & 67 & 76.1 & & & $4.6 \pm 4.6$ \\
\hline $\begin{array}{l}\text { Having relatives } \\
\text { with COVID-19 }\end{array}$ & & & & & 0.5 & 0.47 & \\
\hline Yes & 12 & 29.3 & 29 & 70.7 & & & $5.7 \pm 5$ \\
\hline No & 14 & 23.0 & 47 & 77.0 & & & $4.5 \pm 4.5$ \\
\hline
\end{tabular}

Note: Data $=n(\%)$ or mean \pm standard deviation

COVID-19, coronavirus disease 2019; NMT, nurse midwife technician; CAS, Coronavirus Anxiety Scale; NGO, non-governmental organisation.

$*$, Significance set at $\leq 0.05$.

$\dagger, n=26,25.5 \% ; 末, n=76,74.5 \%$

with their male counterparts $(27.6 \%, n=8)\left(X^{2}=6.8, p=0.01\right)$. There were significant differences in the numbers of respondents who had functional impairement in relation to workplace $\left(X^{2}=8.7, p=0.03\right)$ (Table 2). The prevalence of functional impairment was highest amongst respondents who were working in hospitals $(58.6 \%, n=34)$, with mean WSAS score of $20.6 \pm 10.4$ (Table 2). Furthermore, none of those working in COVID-19 ward $(0 \%, n=0)$ had functional impairement with the lowest mean WSAS score of $5.5 \pm 7.8$.

The demographic characteristics that were found to have significant differences based on Chi-square test were
TABLE 2: Demographic characteristics of respondents associated with functional impairment.

\begin{tabular}{|c|c|c|c|c|c|c|c|}
\hline \multirow[t]{3}{*}{ Characteristics } & \multicolumn{7}{|c|}{ Severe functional impairment } \\
\hline & \multicolumn{2}{|c|}{ Yes $\dagger$} & \multicolumn{2}{|c|}{ No: } & \multicolumn{2}{|c|}{ Statistic } & \multirow{2}{*}{$\begin{array}{l}\text { Mean WSAS } \\
\text { score }\end{array}$} \\
\hline & $n$ & $\%$ & $n$ & $\%$ & $\chi^{2}$ & $p$ & \\
\hline Age & & & & & 1.0 & 0.3 & \\
\hline$\leq 35$ years & 28 & 57.1 & 25 & 47.2 & & & $20.1 \pm 10.4$ \\
\hline$\geq 36$ years & 21 & 42.9 & 28 & 52.8 & & & $15.7 \pm 10.9$ \\
\hline Gender & & & & & 6.8 & $0.01 *$ & \\
\hline Female & 41 & 56.2 & 32 & 43.8 & & & $18.8 \pm 10.4$ \\
\hline Male & 8 & 27.6 & 21 & 72.4 & & & $15.9 \pm 11.7$ \\
\hline Education & & & & & 1.7 & 0.79 & \\
\hline Bachelor's & 28 & 51.9 & 26 & 48.1 & & & $19.2 \pm 9.9$ \\
\hline Certificate & 2 & 66.7 & 1 & 33.3 & & & $22 \pm 7.9$ \\
\hline Diploma & 3 & 37.5 & 5 & 62.5 & & & $18.4 \pm 9.6$ \\
\hline Master's & 14 & 45.2 & 17 & 54.8 & & & $16.3 \pm 21.1$ \\
\hline Doctorate & 2 & 33.3 & 4 & 66.7 & & & $13.3 \pm 14.6$ \\
\hline Nursing cadre & & & & & 0.2 & 0.64 & \\
\hline NMT & 5 & 56.6 & 4 & 44.4 & & & $21.9 \pm 7.7$ \\
\hline Registered nurse & 44 & 47.3 & 49 & 52.7 & & & $17.6 \pm 11$ \\
\hline Employment status & & & & & 1.0 & 0.8 & \\
\hline Full-time & 44 & 48.9 & 46 & 51.1 & & & $18 \pm 10.9$ \\
\hline Part-time & 1 & 50. & 1 & 50.0 & & & $15 \pm 9.9$ \\
\hline Unemployed & 4 & 40.0 & 6 & 60.0 & & & $18.6 \pm 11.7$ \\
\hline Workplace & & & & & 8.7 & $0.03 *$ & \\
\hline Hospital & 34 & 58.6 & 24 & 41.4 & & & $20.6 \pm 10.4$ \\
\hline Nursing college & 11 & 44.0 & 14 & 56.0 & & & $16 \pm 11.5$ \\
\hline COVID-19 ward & 0 & 0.0 & 2 & 100.0 & & & $5.5 \pm 7.8$ \\
\hline NGO & 4 & 23.5 & 13 & 76.5 & & & $13.6 \pm 8.9$ \\
\hline Marital status & & & & & 0.7 & 0.5 & \\
\hline Married & 36 & 50.7 & 35 & 49.3 & & & $18.7 \pm 10.7$ \\
\hline Not married & 13 & 41.9 & 18 & 58.1 & & & $16.4 \pm 10.4$ \\
\hline $\begin{array}{l}\text { Ever diagnosed with } \\
\text { COVID-19 }\end{array}$ & & & & & 1.3 & 0.24 & \\
\hline Yes & 6 & 66.7 & 43 & 46.2 & & & $21.7 \pm 10.8$ \\
\hline No & 3 & 33.3 & 50 & 53.8 & & & $17.6 \pm 10.8$ \\
\hline History of anxiety & & & & & 1.3 & 0.7 & \\
\hline Yes & 15 & 57.7 & 11 & 42.3 & & & $21.2 \pm 9.6$ \\
\hline No & 34 & 44.7 & 42 & 55.3 & & & $16.9 \pm 11$ \\
\hline $\begin{array}{l}\text { Working with } \\
\text { COVID-19 patients }\end{array}$ & & & & & 0.5 & 0.5 & \\
\hline Yes & 8 & 57.1 & 6 & 42.9 & & & $20.3 \pm 12.3$ \\
\hline No & 41 & 46.6 & 47 & 53.4 & & & $17.6 \pm 10.5$ \\
\hline $\begin{array}{l}\text { Having relatives } \\
\text { with COVID-19 }\end{array}$ & & & & & 3.0 & 0.08 & \\
\hline Yes & 24 & 58.5 & 17 & 41.5 & & & $21 \pm 11.2$ \\
\hline No & 25 & 41.0 & 36 & 59.0 & & & $16 \pm 10.1$ \\
\hline
\end{tabular}

Note: Data $=n(\%)$ or mean \pm standard deviation

COVID-19, coronavirus disease 2019; NMT, nurse midwife technician; WSAS, Work and Social Adjustment Scale, NGO, non-governmental organisation.

$*$, Significance set at $\leq 0.05$.

$\dagger, n=49,48 \% ; \ddagger, n=53,52 \%$.

further analysed using one-way ANOVA to determine if there were any significant differences in respondent scores on the CAS and the WSAS based on workplace. The findings revealed that there were significant differences in the respondents' mean scores on the CAS $(F=3.1, p=0.03)$ and the WSAS ( $F=3, p=0.03$ ) based on workplace. Post hoc comparisons using Tukey's honestly significant difference (HSD) test indicated that the WSAS mean score for the respondents working in the hospital (mean $[M]=$ $20.6 \pm 10.4)$ was significantly different $(p=0.05)$ from those working in NGOs $(M=13.6 \pm 8.9)$. However, the WSAS mean scores for respondents working in nursing colleges 
$(M=16 \pm 11.5)$ and COVID-19 wards $(M=5.5 \pm 7.8)$ did not significantly differ from those working in hospital $(p>$ 0.05). Independent samples $t$-tests revealed that female respondents $(M=18.8 \pm 10.4)$ had higher WSAS scores than male respondents $(M=15.9 \pm 11.7)$ and this result was not significant $(t=1.2, p=0.22)$. A further post hoc comparison using the Tukey's HSD test showed that the CAS mean scores of the respondents working in the hospital $(M=6.7 \pm 4.8)$ were significantly different $(p=0.05)$ from those working in NGOs $(M=2.5 \pm 2.7)$. However, the CAS mean score of respondents working in nursing colleges $(M=2.8 \pm 4.2)$ and COVID-19 wards $(M=1.5 \pm 0.7)$ did not significantly differ from those working in hospital $(p>0.05)$.

\section{Reliability and validity of the Coronavirus Anxiety Scale}

This study revealed that both the CAS (Cronbach's alpha = 0.9 ) and the WSAS (Cronbach's alpha $=0.8$ ) are reliable instruments with good internal consistency for assessing COVID-19-related anxiety and functional impairment in the local setting. A further analysis using the WSAS as a gold standard, the CAS (cut off $\geq 9$ ) was found to be a valid (sensitivity $=73.1 \%$, specificity $=60.5 \%, \mathrm{NPV}=38.8 \%$ and $\mathrm{PPV}=86.8 \%)$ and accurate $(\mathrm{AUC}=0.73$ ) instrument for measuring COVID-19-related anxiety locally. This study found that the optimum cut-off score of the CAS was $>3$ (Youden's index $=0.34$ ), which was lower than the original optimum cut-off score of $>9$.

\section{Discussion}

The results of this study are less conclusive considering that the sample size used was small. Nonetheless, COVID-19related anxiety is one of the mental health problems affecting nurses. The primary aim of this study was to assess COVID19-related anxiety and functional impairment amongst nurses in Malawi, with the secondary aim being to determine the reliability and validity of the CAS. In this study, more than a quarter of nurses $(25.5 \%, n=26)$ were found to have COVID-19-related anxiety. This is comparable with a prevalence of COVID-19-related anxiety that was found amongst nurses in China (27.9\%). ${ }^{16}$ However, the prevalence of COVID-19-related anxiety found in this study was higher than a pooled prevalence of COVID-19-related anxiety amongst health workers (23.2\%) that was reported by a systematic review. ${ }^{7}$ This may be explained by the literature, which asserted that nurses usually experience strong emotional reactions to the COVID-19 virus including anxiety, which impact their work. ${ }^{2}$ In this study, almost half of the nurses $(48 \%, n=49)$ had self-reported functional impairement related to COVID-19. Mental health problems can significantly reduce the quality of care offered by nurses. ${ }^{17}$ This is corroborated by Pragholapati and colleagues who asserted that COVID-19-related anxiety can interfere with performance of nurses in their duties and reduce their selfefficacy levels. ${ }^{9}$
This study suggests that many nurses who work in hospitals experience high levels of anxiety $(36.2 \%, n=21$, Mean CAS score $=6.7 \pm 4.8)$ and functional impairment $(58.6 \%, n=34$, mean WSAS score $=20.6 \pm 10.4)$. As frontline healthcare workers, nurses may be vulnerable to negative mental health effects from COVID-19. The nature of care itself and new ways of working are potentially highly stressful for nurses who are being overwhelmed with increased workload and demands to accommodate new protocols. ${ }^{2}$ Literature indicated that it is necessary to pay attention to the psychological issues of nurses during and after caring for patients with COVID-19. ${ }^{17}$ Supporting nurses practically and psychologically helps in preserving their health especially when work-related stress levels are too high. ${ }^{2}$

Hospitals should provide sufficient support to nurses, including personal protective equipment, psychological screening for nurses and psychological support. ${ }^{17}$ This is crucial because nurses may not be able to recognise and deal with their own mental health problems whilst they provide care to COVID-19 patients. This is supported by a body of literature, which suggested that those injured by stress may be the last to recognise it and individuals often do not prioritise taking good care of themselves. ${ }^{2}$ It is necessary that nurses with symptoms of anxiety seek help from psychotherapists to evaluate them and help them deal with potential stress. ${ }^{18}$ This is helpful because nurses must be able to look after themselves if they are going to properly look after others. ${ }^{2}$ However, nurses are generally trained to look after others and not self so that in many instances they need others including colleagues, friends and managers to remind them to think of themselves. ${ }^{2}$

Reliable and valid instruments are needed for nurses to detect and validate their COVID-19-related anxiety. As a result of concern about the variation of performance of screening instruments in different populations and settings, ${ }^{19}$ it was necessary to measure the validity of the CAS in the local setting. This study showed that the CAS was able to distinguish nurses with anxiety from those without anxiety (sensitivity $=73.1 \%$, specificity $=60.5 \%$, AUC $=0.73$, cut-off $\geq 9$ ) in the local setting. The results support the CAS as an effective, reliable (Cronbach's alpha $=0.9$ ) and valid instrument for clinical research and practice. .,12,14

This study had some limitations because it was conducted online and those without Internet access or without adequate Internet bundles could not be involved in the study. These results are biased towards registered nurses who managed to respond to online questionnaire because they have a relatively better income as compared with NMTs. Future research should consider using an alternative means of getting data such as face-to-face data collection methods to ensure adequate representation of all cadres of nurses. Furthermore, the results of this study heavily relied on respondents' self-reports, which may have yielded recall bias because nurses were asked to recall events that happened two weeks or more ago. There was no common attention 
check item (instructed response item) embedded within the online survey. Consequently, the validity of the CAS might have been affected by careless responses.

\section{Conclusion}

This study suggested that the prevalence of COVID-19related anxiety is high amongst nurses in Malawi. Most nurses experience functional impairment because of COVID-19. Furthermore, this study has confirmed that the CAS is a valid instrument which is effective in detecting COVID-19-related anxiety amongst nurses. The CAS could be a suitable instrument for assessing COVID-19-related anxiety amongst nurses.

\section{Implications for practice}

Considering that prevalence of COVID-19-related anxiety is high amongst nurses, it is necessary to screen nurses for the COVID-19-related anxiety and functional impairment and provide them effective psychosocial interventions. Mental health interventions targeting nurses should include preparedness to reduce the effects of COVID-19 on their mental health and well-being. Nurses need moral, psychological and material support from their employers and colleagues. It is important that policymakers allocate adequate funding to mental health services targeting nurses during pandemics. There is a need to conduct future research on mental health interventions that might be used to assist nurses with COVID-19-related anxiety and functional impairment.

\section{Acknowledgements}

The author would like to acknowledge the invaluable contribution of all who assisted with data collection and reviewing of this article.

\section{Competing interests}

The author declares that he has no financial or personal relationships that may have inappropriately influenced him in the writing of this article.

\section{Author's contributions}

I declare that I am the sole author of this research article..

\section{Funding information}

The author received no financial support for the research, authorship and/or publication of this article.

\section{Data availability}

Data sharing is not applicable to this study as no new data were created or analysed in this study.

\section{Disclaimer}

The views and opinions expressed in this article are those of the author and do not necessarily reflect the official policy or position of any affiliated agency of the author.

\section{References}

1. Shanafelt T, Ripp J, Trockel M. Understanding and addressing sources of anxiety among health care professionals during the COVID-19 pandemic. JAMA. 2020;323(21):2133-2134. https://doi.org/10.1001/jama.2020.5893

2. Maben J, Bridges J. Covid-19: Supporting nurses' psychological and mental health J Clin Nurs. 2020;29(15-16):2742-2750. https://doi.org/10.1111/jocn.15307

3. Nelson SM, Lee-Winn AE. The mental turmoil of hospital nurses in the COVID-19 pandemic. Psychol Trauma. 2020;12(1):S126-S127. https://doi.org/10.1037/ tra0000810

4. Ahorsu DK, Lin C-Y, Imani V, Saffari M, Griffiths MD, Pakpour AH. The fear of COVID-19 scale: Development and initial validation. Int J Ment Health Addict. 2020. https://doi.org/10.1007/s11469-020-00270-8

5. Evren C, Evren B, Dalbudak E, Topcu M, Kutlu N. Measuring anxiety related to COVID-19: A Turkish validation study of the Coronavirus Anxiety Scale. Death Stud. 2020:1-7. https://doi.org/10.1080/07481187.2020.1774969

6. Wong AH, Pacella-LaBarbara ML, Ray JM, Ranney ML, Chang BP. Healing the healer: Protecting emergency health care workers' mental health during COVID-19. Ann Emer: Med. 2020;76(4):379-384. https://doi.org/10.1016/j.annemergmed.2020.04.041

7. Pappa S, Ntella V, Giannakas T, Giannakoulis VG, Papoutsi E, Katsaounou P. Prevalence of depression, anxiety, and insomnia among healthcare worker during the COVID-19 pandemic: A systematic review and meta-analysis. Brain Behav Immun. 2020;88:901-907. https://doi.org/10.1016/j.bbi.2020.05.026

8. Khanal P, Devkota N, Dahal M, Paudel K, Joshi D. Mental health impacts among health workers during COVID-19 in a low resource setting: A cross-sectiona survey from Nepal. Global Health. 2020;16(1):1-12. https://doi.org/10.1186/ s12992-020-00621-z

9. Pragholapati A. Self-efficacy of nurses during the pandemic Covid-19 [homepage on the Internet]. Bandung, Indonesia: Universitas Pendidikan Indonesia; 2020 on the Internet]. Bandung, Indonesia: Universitas Pendidikan Indonesia; 2020 [cited 2020 Sept 12]; p. 1-7. Available from: https://www.acad
edu/43045687/Self_Efficacy_Of_Nurses_During_The_Pandemic_Covid_19

10. Nurses and Midwives Council of Malawi. Scope of practice for all cadres of nursing and midwifery. Mzuzu: Katoto Printing Press; 2009.

11. Jones $S$, Carley S, Harrison M. An introduction to power and sample size estimation. Emerg Med J. 2003;20(5):453. https://doi.org/10.1136/emj.20.5.453

12. Lee SA. Coronavirus Anxiety Scale: A brief mental health screener for COVID-19 related anxiety. Death Stud. 2020;44(7):393-401. https://doi.org/10.1080/07481 187.2020.1748481

13. Sivo SA, Saunders C, Chang Q, Jiang JJ. How low should you go? Low response rates and the validity of inference in IS questionnaire research. I Assoc Inform Syst. 2006;7(1):17. https://doi.org/10.17705/1jais.00093

14. Lee SA, Mathis AA, Jobe MC, Pappalardo EA. Clinically significant fear and anxiety of COVID-19: A psychometric examination of the Coronavirus Anxiety Scale. Psychiatry Res. 2020;290:113112. https://doi.org/10.1016/j.psychres.2020.113112

15. Mundt JC, Marks IM, Shear MK, Greist JM. The Work and Social Adjustment Scale: A simple measure of impairment in functioning. $\mathrm{Br} J$ Psychiatry. 2002;180(5):461-464. https://doi.org/10.1192/bjp.180.5.461

16. Zhu J, Sun L, Zhang L, et al. Prevalence and influencing factors of anxiety and depression symptoms in the first-line medical staff fighting against COVID-19 in Gansu. Frontiers in psychiatry. 2020;11. https://doi.org/10.3389/fpsyt.2020.00386

17. Puradollah M. Necessity of attention to mental health of the front line nurses against COVID-19: A forgotten requirement. Int J Community Based Nurs Midwifery. 2020;8(3):280.

18. Huang L, Lin G, Tang L, Yu L, Zhou Z. Special attention to nurses' protection during the COVID-19 epidemic. Crit Care. 2020;24:120. https://doi.org/10.1186/s13054020-2841-7

19. Bossuyt, PM, Reitsma JB, Bruns DE, et al. STARD 2015: An updated list of essential items for reporting diagnostic accuracy studies. Clinical chemistry 2015;61(12):1446-1452. https://doi.org/10.1373/clinchem.2015.246280 